\title{
Healthy lifestyle as a preventive measure against victimization among school-going adolescents
}

Nadia Shah, ${ }^{1}$ Saadiyah Rao, ${ }^{1}$ Sumera Inam, ${ }^{1}$ Nida Jawed, ${ }^{1}$ Charlotte Siiger, ${ }^{2}$ Syed Omair Adil ${ }^{1}$ and Kashif Shafique ${ }^{1,3}$

${ }^{1}$ Dow University of Health Sciences, Pakistan. ${ }^{2}$ Metropolitan University College, Copenhagen, Denmark. ${ }^{3}$ Institute of Health and Wellbeing, University of Glasgow, United Kingdom. (Correspondence to: Kashif Shafique: kashif.shafique@glasgow.ac.uk).

\begin{abstract}
Background: Bullying and violence are problems of aggression in adolescents. Healthy lifestyle practices are common health promotion approaches in school settings; however, their association with aggressive behaviours in school-going adolescents is less explored.

Aims: This study examined the associations of healthy lifestyle behaviours including good hygiene, physical activity, recommended diet and refrainment from tobacco use with bully victimization and violence among adolescents.

Methods: Data were obtained from the Global School Health Survey conducted in Pakistan (2009). The study population consisted of school-going adolescents aged 13 to 15 years. We constructed our final dataset using information from 4102 participants. Association of healthy lifestyle behaviours with bully victimization and violence experience were assessed using multivariate logistic regression.

Results: Results indicate lower odds of being bullied (good hygiene: OR=0.62, 95\% CI 0.50-0.76, $P<0.001$; physical activity: OR=0.55, 95\% CI 0.40-0.75, P <0.001; abstinence from tobacco: OR=0.43, 95\% CI 0.30-0.63, P<0.001) and lower odds of violence (good hygiene: $\mathrm{OR}=0.68,95 \% \mathrm{CI} 0.55-0.84, \mathrm{P}<0.001$; physical activity: $\mathrm{OR}=0.55,95 \% \mathrm{CI} 0.43-0.71, \mathrm{P}<0.001$; abstinence from tobacco: $\mathrm{OR}=0.48,95 \% \mathrm{CI} 0.32-0.72, \mathrm{P}<0.001)$, after controlling for socio-demographic and potential confounding factors.

Conclusions: Our study supports the significance of healthy lifestyle as a preventive measure against victimization. Anti-bullying programmes focusing on social-emotional skill development may also consider promotion of healthy lifestyle behaviours among adolescents, aiming at reducing victimization and its related consequences.

Keywords: physical activity, tobacco, adolescents, bully victimization, violence

Citation: Shah N; Rao S; Inam S; Jawed N; Siiger C; Adil SO; et al. Healthy lifestyle as a preventive measure against victimization among school-going adolescents. East Mediterr Health J. 2019;25(9):604-612 https://doi.org/10.26719/emhj.19.007

Received: 03/09/17; accepted: 12/02/18

Copyright ( ) World Health Organization (WHO) 2019. Some rights reserved. This work is available under the CC BY-NC-SA 3.0 IGO license (https:// creativecommons.org/licenses/by-nc-sa/3.o/igo)
\end{abstract}

\section{Introduction}

Bullying is referred to as a specific type of aggression, where a bully victimizes a less powerful individual either by direct physical aggression or verbal abuse and public humiliation. Violence, a form of externalizing behaviour of bullies, is an intentional use of physical force or power against another person with a high possibility of injury (1). Boys are more commonly found to be victims of direct physical aggression, while girls are mostly targeted through indirect forms of bullying such as name-calling, threats, spreading rumours and shunning $(2,3)$. Moreover, negative physical and psychological consequences are also reported in adolescents including lower self-efficacy, involvement in anti-social behaviour and low educational attainment (4). In an international survey, 15686 adolescents reported higher frequency of males than females to be both perpetrators and targets of bullying and experiencing bullying was associated with poorer psychosocial adjustments (5). Nearly $50 \%$ of adolescents have experienced bully victimization in low- and middle-income countries including Pakistan, emphasizing the need to explore the determinants associated with bullying behaviour among this age group. A recent study among school children of six graders reported that $46.4 \%$ of girls vs. $72.6 \%$ boys were bullied (6).

Adolescence is an important period for health promotion initiatives since key behaviour patterns and lifestyle that influence lifelong health usually originate in this period (7). These behaviours include healthy eating habits, hygienic practices, physical activity and abstinence from health risk behaviours like smoking and substance use (8-14), while adapting unhealthy lifestyle poses a substantial risk to health. Low physical activity as well as reduced fruits and vegetables intake is considered to be responsible for growing childhood obesity, which in turn has been linked with bully victimization $(10,11)$. A behavioural study of 5749 Canadian boys and girls reported higher odds of peer victimization among overweight and obese adolescents. Similarly, risk-taking behaviours in adolescence have been identified as important determinants of bullying or violence among adolescents (12-14).

Prior research has examined the relationship between bully victimization and a limited range of mental health risk behaviours in Pakistani adolescents. Poor school performance has also been significantly associated with 
violence-related behaviours, i.e. verbal abuse, physical fighting and bullying (15). Similarly, there is limited literature on violence among children. However, the literature is mostly focused on the qualitative analysis of macro risk factors, such as illiteracy, large family size, poverty, poor legal protection, witnessing domestic violence and unemployment, which creates an enabling environment for violent behaviour among children (16). Healthy lifestyle and risk behaviours in relation to bully victimization and violence have been less plentiful. Although child abuse can be defined universally, yet the diverse types of abuse, their existence in different societies, and more importantly interventions for its prevention and control, need to focus on the specific cultural contexts within each country.

In this context the identification of health risk behaviours, and their association with bully victimization, may explicitly help to improve preventive strategies in reducing the risk of bully victimization and violence among adolescents in low- and middle-income countries in general, and Pakistan in particular. Thus, the current study aimed to examine the associations of healthy lifestyle behaviours including recommended diet, good hygiene, physical activity and no tobacco use with bully victimization and violence among adolescents in Pakistan by using the Global School-Based Student Health Survey (GSHS).

\section{Methods}

This study is based on secondary analysis of national data from GSHS conducted in Pakistan (2009). GSHS is a collaborative surveillance project of the World Health Organization (WHO) and Centers of Disease Control and Prevention (CDC). It is a standardized school based survey targeting students aged 13-15 years with the purpose to monitor the prevalence of health risk behaviours and protective factors. GSHS has a common school-based methodology to gauge and observe risk and protective factors among students in many countries. Pakistan GSHS comprises mental health, physical activity, dietary behaviours, protective factors, hygiene, tobacco use, and violence sections. The students were selected by multistage cluster sampling. A total of 5192 students participated with an overall response rate of $76 \%$.

The protocol of sampling, survey administration, questionnaires, codebook and data for the survey used are available at (http://www.cdc.gov/gshs/countries/ eastmediter/pakistan.htm). Full details about GSHS are available at (http://www.cdc.gov/gshs/).

\section{Materials and measures}

Sex and age (in years) of the participants were included as documented in the survey, while socioeconomic status (SES) was derived from the question; "During the past 30 days, how often did you go hungry because there was not enough food in your home?" (Response options: "never" to "rarely" as 'average' and "sometimes" to "always" as 'below average') (17). We used 'Hunger' as a proxy vari- able for SES as no other variable on SES was available in GSHS. The use of hunger as an indicator of SES accords with earlier studies (18). The motivation for inclusion of this variable was to consider the relative effects of poverty on risk of bullying and violence. The body mass index (BMI) was calculated as weight $(\mathrm{kg}) /$ height $(\mathrm{m})$. It was categorized according to WHO standard BMI percentiles for children. The following protective measures were included: close friends: "How many close friends do you have?" (recoded: 0 = 'no'; 1 to $\geq 3$ = 'yes'), parental check: "During the past 30 days, how often did your parents or guardians really know what you were doing with your free time?" (recoded: "never" to "rarely" = 'no'; “sometimes" to "always" = 'yes') (19); and parental understanding: "During the past 30 days, how often did your parents or guardians understand your problems and worries?" (recoded: "never" to "rarely" = "no'; "sometimes" to "always" = 'yes').

\section{Healthy lifestyle behaviours}

Healthy lifestyle behaviours were defined as a combination of recommended diet, good hygienic practices, physical activity and no tobacco use, based on literature (20). All four behaviours were measured and recorded as dichotomous variables.

Dietary practices were determined by daily consumption of fruits and vegetables based on WHO recommendations. The following two questions were included. Vegetable consumption: "During the past 30 days, how many times per day did you usually eat vegetables?"; fruit consumption: "During the past 30 days, how many times per day did you usually eat fruit, such as bananas, apples, oranges, melon, guava, mango, or peaches?" WHO recommended diet comprising of two or more servings of fruit and three or more servings of vegetables per day was classified as good nutrition and anything under the stated values as poor nutrition (21).

Hygienic practices were categorized as 'poor' hygiene and 'good' hygiene according to the practices of brushing teeth, washing hands and using soap based on the following four questions: "During the past 30 days, how many times per day you usually clean or brush your teeth?", "During the past 30 days, how often did you wash your hands before eating?", "During the past 30 days, how often did you usually wash hands after using the toilet or latrine?" and "During the past 30 days, how often did you use soap when washing hands? (22).

Physical activity was evaluated as "How much time do you spend during a typical or usual day sitting and watching television, playing computer games, talking with friends, or doing other sitting activities such as playing board games or cards?" Being 'active' was categorized as those who were inactive for less than two hours/day (23). Tobacco use comprised both smoked and smokeless tobacco and was measured as follows: smoking as, "During the past 30 days, on how many days did you smoke cigarettes?" (Recoded: o days = 'no'; >130 days = 'yes') and other tobacco usage as "During the past 30 days, on how many days did you use hukka, bidi, 
niswar, shisha, or main puri ?" (a paste made of crushed tobacco, beetle nut, and catechu) (Recoded: o days = 'no'; $>1-30$ days $=$ 'yes') $(24)$.

\section{Outcome measures}

Bully victimization and violence were the main focus of our study. Students were classified as bully victims if they responded to the question "During the past 30 days, on how many days were you bullied?" with any answer greater than three days as 'being frequently bullied'(5) and at least on one day as 'being bullied'. By definition, 'being frequently bullied' is included in 'being bullied' whereas those who were 'not ever being bullied' were categorized as 'not being bullied' (20). Violence was measured as "During the past 12 months, how many times were you in a physical fight?" (Recoded: o times = 'no'; $\geq 1$ = 'yes') (13).

\section{Statistical analyses}

Analyses were conducted using SAS version 9.1.3. We opted to use complex survey data analysis for multistage cluster sampling design used in GSHS. Weight, stratum, and primary sampling units (PSU) were used. We used Chi square tests to determine the statistical significance of the relation between the outcome variables; 'being bullied' and 'violence' and relevant explanatory variables obtained from the literature including age, sex, SES, BMI, having close friends, parental understanding, parental check, and healthy lifestyle behaviours (14,17,20,23-25). Binary logistic regression analyses (univariate and multivariate) were conducted to estimate association between relevant predictor variables and being bullied and violence. The study sample included 5192 school-going adolescents of Pakistan. We constructed the final dataset using information from 4102 participants, after excluding 1090 participants due to missing data on the variables selected for this study. Preliminary analysis demonstrated no difference in baseline characteristics of the missing group.

\section{Results}

The final analysis was conducted on $59.8 \%$ (3041) boys and $40.2 \%$ (1061) girls, aged 11-16 years or older. Table 1 shows the prevalence of being bullied and violence, and their association with healthy lifestyle behaviours, sociodemographics, and other potential factors. We observed frequency of being bullied among boys to be $44.5 \%$ and violence $46.5 \%$, whereas among girls it was $35.6 \%$ and $22.1 \%$ respectively. $26.1 \%$ (1096) school children were ever bullied, whereas $14.8 \%$ (657) were frequently bullied and $36.7 \%$ (1654) adolescents were victims of violence.

Healthy lifestyle behaviours such as good hygienic practices $(P<0.001)$, physical activity $(P<0.001)$, and no tobacco use $(P<0.001)$ were negatively associated with being bullied and violence. Below average SES $(P<$ 0.001) and parental understanding $(P=0.012)$ were also significantly associated with being bullied. In addition below average SES $(P=0.020)$, sex $(P<0.001)$, and parental understanding $(P<0.001)$ were also significantly associated with violence.
Univariate logistic regression revealed that adolescents practicing healthy lifestyle behaviours such as good hygiene, physical activity and no tobacco use were significantly less likely to be victims of bully and violence. In contrast, adolescents belonging to below average SES inferred higher odds for both being bullied $(\mathrm{OR}=1.58,95 \% \mathrm{CI}: 1.20-2.08, \mathrm{P}$ value $<0.001)$ and violence $(\mathrm{OR}=1.44,95 \% \mathrm{CI}: 1.04-2.00, P=0.026)$. Female respondents $(\mathrm{OR}=0.32,95 \% \mathrm{CI}: 0.22-0.46, \mathrm{P}<0.001)$ were significantly less likely to be victim of violence as compared to their male counterparts. High parental understanding showed significant lower odds of being bullied $(\mathrm{OR}=0.76,95 \% \mathrm{CI}$ : $0.61-0.95, P=0.015)$ and violence $(\mathrm{OR}=0.71,95 \% \mathrm{CI}: 0.60-$ $0.84, P<0.001$ ) (Table 2).

On multivariate analysis (Table 3 ) a slight difference in odds ratio was observed for all the factors that were significant in the univariate analysis. Analyses of healthy lifestyle behaviour showed that good hygienic practices (OR=0.62, 95\% CI: 0.50-0.76, P < 0.001); physically active lifestyle (OR=0.55, 95\% CI: 0.40-0.75, P<0.001) and no tobacco use $(\mathrm{OR}=0.43,95 \% \mathrm{CI}: 0.30-0.63, P<0.001)$ were less likely to be bullied; a similar association was noted for victims of violence. Furthermore, results showed higher odds ( $\mathrm{OR}=1.48,95 \% \mathrm{CI}: 1.14-1.93, \mathrm{P}=0.003)$ of being bullied for adolescents belonging to below average SES. Female adolescents (OR=0.37, 95\% CI: 0.25-0.54, P< 0.001) as compared to males had statistically significant lower odds of being victims of violence after adjustment for multiple covariates.

\section{Discussion}

Adolescents, who had good hygienic behaviour, were physically active and non-tobacco users were less likely to be victims of bullying and violence. These associations remained significant after controlling for potential confounding factors. The overall prevalence of violence among school children in Pakistan was found to be $36.7 \%$ and that of being bullied $40.9 \%$, of which $15 \%$ were frequently bullied. Previously published studies on bullying among school children in low- and middle-income countries found considerable variations in bullying prevalence ranging from $7.8 \%$ in Tajikistan to $60.9 \%$ in Zambia with an average of $34.2 \%(5,20)$. We also observed that boys faced remarkably higher bully and violence problems than girls and this finding remained fairly comparable with previous evidence (59\% and 39\% among boys and girls respectively) (20). The male predominance in physical violence compared to females is not surprising (26). In Pakistan, a study conducted among younger adolescents found that boys are heavily socialized in the norms, morals and values of rigid masculinity (27). Another study concluded that sex discrimination in parental practices when disciplining children is common and parents teach girls to be submissive (28).

We observed a lower risk of bully victimization and violence among adolescents who do not use tobacco. This indicates that even adaptation of smoking behaviour by youngsters does not decrease their risk of bully 


\begin{tabular}{|c|c|c|c|c|c|c|}
\hline \multirow[t]{2}{*}{ Variables } & \multicolumn{3}{|c|}{ Being bullied } & \multicolumn{3}{|c|}{ Violence } \\
\hline & $\begin{array}{c}\text { No } \\
\mathbf{N}^{*}(\%){ }^{* *}\end{array}$ & $\begin{array}{c}\text { Yes } \\
\mathbf{N}^{*}(\%)\end{array}$ & $P$-value & $\begin{array}{c}\text { No } \\
\mathbf{N}^{*}(\%)\end{array}$ & $\begin{array}{c}\text { Yes } \\
\mathbf{N}^{*}(\%)\end{array}$ & P-value \\
\hline \multicolumn{7}{|l|}{ Socio-demographics } \\
\hline \multicolumn{7}{|l|}{ Age } \\
\hline$<=14$ & $1394(58.6)$ & $1059(41.4)$ & 0.682 & $1464(64.5)$ & $989(35.5)$ & 0.326 \\
\hline$>14$ & $955(59.5)$ & $694(40.1)$ & & $984(61.4)$ & $665(38.6)$ & \\
\hline \multicolumn{7}{|l|}{ Sex } \\
\hline Male & $1676(55.5)$ & $1365(44.5)$ & 0.198 & $1630(53.5)$ & $1411(46.5)$ & $<0.001$ \\
\hline Female & $673(64.4)$ & $388(35.6)$ & & $818(77.9)$ & $243(22.1)$ & \\
\hline \multicolumn{7}{|l|}{ SES } \\
\hline Average & $1978(61.2)$ & $1348(38.8)$ & $<0.001$ & $2025(64.9)$ & $1301(35.1)$ & 0.020 \\
\hline Below average & $371(49.8)$ & $405(50.2)$ & & $423(56.1)$ & $353(43.9)$ & \\
\hline \multicolumn{7}{|l|}{ BMI } \\
\hline Normal weight & $1993(84.2)$ & $1475(83.4)$ & 0.537 & $2069(63.1)$ & $1420(36.9)$ & 0.591 \\
\hline Over weight & $344(15.8)$ & $264(16.6)$ & & $379(64.3)$ & $234(35.7)$ & \\
\hline \multicolumn{7}{|l|}{ Parental understanding } \\
\hline Low level of understanding & $1030(55.5)$ & $856(44.5)$ & 0.012 & $1051(59.0)$ & $835(41.0)$ & $<0.001$ \\
\hline High level of understanding & $1319(62.0)$ & $897(38.0)$ & & $1397(66.8)$ & $819(33.2)$ & \\
\hline \multicolumn{7}{|l|}{ Parental check } \\
\hline No & $1152(57.7)$ & $903(42.3)$ & 0.276 & $1191(61.6)$ & $864(38.4)$ & 0.074 \\
\hline Yes & $1197(60.5)$ & $850(39.5)$ & & $1257(64.9)$ & $790(35.1)$ & \\
\hline \multicolumn{7}{|l|}{ Friends } \\
\hline No & $162(59.1)$ & $132(40.9)$ & 0.993 & $184(66.1)$ & $110(33.9)$ & 0.257 \\
\hline Yes & $2187(59.1)$ & $1621(40.9)$ & & $2264(63.1)$ & $1544(36.9)$ & \\
\hline \multicolumn{7}{|l|}{ Healthy lifestyle behaviours } \\
\hline \multicolumn{7}{|l|}{ Nutrition } \\
\hline Not recommended & $2220(59.2)$ & $1642(40.8)$ & 0.708 & $2309(63.4)$ & $1553(36.6)$ & 0.623 \\
\hline Recommended & $129(57.7)$ & $111(42.3)$ & & $139(61.4)$ & $101(38.6)$ & \\
\hline \multicolumn{7}{|l|}{ Hygiene } \\
\hline Poor & $1293(53.2)$ & $1226(46.8)$ & $<0.001$ & $1365(57.0)$ & $1154(43.0)$ & $<0.001$ \\
\hline Good & $1056(67.3)$ & $527(32.7)$ & & $1083(72.1)$ & $500(27.9)$ & \\
\hline \multicolumn{7}{|l|}{ Physical activity } \\
\hline No & $2227(60.3)$ & 1574(39.7) & $<0.001$ & $136(49.7)$ & $165(50.3)$ & $<0.001$ \\
\hline Yes & $122(44.5)$ & $179(55.5)$ & & $2312(64.4)$ & $1489(35.6)$ & \\
\hline \multicolumn{7}{|l|}{ Tobacco and other products } \\
\hline Yes & $39(33.7)$ & $80(66.3)$ & $<0.001$ & $40(35.1)$ & $79(64.9)$ & $<0.001$ \\
\hline No & $2310(59.7)$ & $1673(40.30)$ & & $2480(64.0)$ & 1575(36.6) & \\
\hline
\end{tabular}

Final dataset was constructed using information from 4102 participants, after excluding 1090 participants due to missing information.

*Unweighted Count; **Weighted percentage

victimization (29). One possibility could be that this behaviour might not be accepted by fellow students, thus subjecting smokers to bullying. In contrast, it is also possible that bully victimization might have led the victims to smoking, since earlier studies have reported a positive association between being bullied and tobacco smoking (5). In Pakistan's patriarchal culture, children's food and shelter are considered a priority over risky behaviours, which are often overlooked. Our study also revealed lower odds of bully victimization and violence among adolescents practicing good hygienic practices. There is some suggestion in an earlier study that adolescents who do not follow good hygienic practices might suffer from stigmatization by peers, subjecting them to social rejection, which may also lead to psychosocial issues including anxiety, depression and even violent behaviour (30).

Benefits of a physically active lifestyle are advocated 


\begin{tabular}{|c|c|c|c|c|}
\hline \multirow[t]{2}{*}{ Variables } & \multicolumn{2}{|c|}{ Being bullied } & \multicolumn{2}{|c|}{ Violence } \\
\hline & OR $(95 \% \mathrm{CI})$ & $P$-value & OR $(95 \% \mathrm{CI})$ & P-value \\
\hline \multicolumn{5}{|l|}{ Socio-demographics } \\
\hline \multicolumn{5}{|l|}{ Age } \\
\hline$<=14$ & 1 & & 1 & \\
\hline$>14$ & $0.95(0.74-1.21)$ & 0.683 & $1.14(0.86-1.50)$ & 0.342 \\
\hline \multicolumn{5}{|l|}{ Sex } \\
\hline Male & 1 & & 1 & \\
\hline Female & $0.68(0.38-1.24)$ & 0.216 & $0.32(0.22-0.46)$ & $<0.001$ \\
\hline \multicolumn{5}{|l|}{ SES } \\
\hline Average & 1 & & 1 & \\
\hline Below average & $1.58(1.20-2.08)$ & $<0.001$ & $1.44(1.04-2.00)$ & 0.026 \\
\hline \multicolumn{5}{|l|}{ BMI } \\
\hline Over weight & 1 & & 1 & \\
\hline Normal weight & $0.93(0.74-1.16)$ & 0.527 & $1.05(0.86-1.28)$ & 0.604 \\
\hline \multicolumn{5}{|l|}{ Parental understanding } \\
\hline Low level of understanding & 1 & & 1 & \\
\hline High level of understanding & $0.76(0.61-0.95)$ & 0.015 & $0.71(0.60-0.84)$ & $<0.001$ \\
\hline \multicolumn{5}{|l|}{ Parental check } \\
\hline No & 1 & & 1 & \\
\hline Yes & $0.89(0.73-1.09)$ & 0.268 & $0.86(0.73-1.02)$ & 0.091 \\
\hline \multicolumn{5}{|l|}{ Friends } \\
\hline No & 1 & & 1 & \\
\hline Yes & $1.00(0.74-1.34)$ & 0.993 & $1.14(0.89-1.46)$ & 0.287 \\
\hline \multicolumn{5}{|l|}{ Healthy lifestyle behaviours } \\
\hline \multicolumn{5}{|l|}{ Nutrition } \\
\hline Not recommended & 1 & & 1 & \\
\hline Recommended & $1.06(0.76-1.47)$ & 0.707 & $1.08(0.77-1.52)$ & 0.623 \\
\hline \multicolumn{5}{|l|}{ Hygiene } \\
\hline Poor & 1 & & 1 & \\
\hline Good & $0.55(0.42-0.71)$ & $<0.001$ & $0.51(0.40-0.64)$ & $<0.001$ \\
\hline \multicolumn{5}{|l|}{ Physical activity } \\
\hline No & 1 & & 1 & \\
\hline Yes & $0.52(0.38-0.72)$ & $<0.001$ & $0.54(0.43-0.68)$ & $<0.001$ \\
\hline \multicolumn{5}{|l|}{ Tobacco and other products } \\
\hline Yes & 1 & & 1 & \\
\hline No & $0.34(0.24-0.48)$ & $<0.001$ & $0.30(0.20-0.44)$ & $<0.001$ \\
\hline
\end{tabular}

OR = odds ratio; $C I=$ confidence interval; statistically significant $<0.05$

throughout the literature and this study reinforces the significance of an active lifestyle. Our results showed that the risk of being bullied and violence was $45 \%$ lower in children who are physically active. Thus, it can be perceived that physical activity infers a protective mechanism against victimization. Active children are physically fit and thus may protect themselves against bullying and violence (20).

It has been established that overweight and obese children are more likely to be victimized (11,25). Turagabeci et al. examined the association of bullying and violence with diet, and reported that adolescents following a diet with low intake of fruits and vegetables were at an increased risk of being bullied and encountering violence (20). However, our study found a non-significant association, which could partly be explained by the fact that majority of adolescents' actual dietary intake does not match the recommended daily allowances of fruits and vegetables, and perhaps partly by food insecurity (31).

Although our focus was not to explore food and vegetable intake among adolescents, we found an alarming percentage of adolescents who do not consume 


\begin{tabular}{|c|c|c|c|c|}
\hline \multirow[t]{2}{*}{ Variables } & \multicolumn{2}{|c|}{ Being bullied $^{1}$} & \multicolumn{2}{|c|}{ Violence $^{2}$} \\
\hline & $\operatorname{AOR}(95 \% \mathrm{CI})$ & $P$-value & $\operatorname{AOR}(95 \% \mathrm{CI})$ & $P$-value \\
\hline \multicolumn{5}{|l|}{ Socio-demographics } \\
\hline \multicolumn{5}{|l|}{ Sex } \\
\hline Male & 1 & & 1 & \\
\hline Female & $0.82(0.44-1.53)$ & 0.546 & $0.37(0.25-0.54)$ & $<0.001$ \\
\hline \multicolumn{5}{|l|}{ SES } \\
\hline Average & 1 & & 1 & \\
\hline Below Average & $1.48(1.14-1.93)$ & 0.003 & $1.32(0.97-1.80)$ & 0.073 \\
\hline \multicolumn{5}{|l|}{ Parental understanding } \\
\hline Low level of understanding & 1 & & 1 & \\
\hline High level of understanding & $0.88(0.72-1.08)$ & 0.249 & $0.89(0.75-1.04)$ & 0.154 \\
\hline \multicolumn{5}{|l|}{ Parental check } \\
\hline No & - & & 1 & \\
\hline Yes & & & $1.01(0.87-1.18)$ & 0.828 \\
\hline \multicolumn{5}{|l|}{ Healthy lifestyle behaviours } \\
\hline \multicolumn{5}{|l|}{ Nutrition } \\
\hline Not recommended & - & & - & \\
\hline \multicolumn{5}{|l|}{ Recommended } \\
\hline \multicolumn{5}{|l|}{ Hygiene } \\
\hline Poor & 1 & & 1 & \\
\hline Good & $0.62(0.50-0.76)$ & $<0.001$ & $0.68(0.55-0.84)$ & $<0.001$ \\
\hline \multicolumn{5}{|l|}{ Physical activity } \\
\hline No & 1 & & 1 & \\
\hline Yes & $0.55(0.40-0.75)$ & $<0.001$ & $0.55(0.43-0.71)$ & $<0.001$ \\
\hline \multicolumn{5}{|l|}{ Tobacco and other products } \\
\hline Yes & 1 & & 1 & \\
\hline No & $0.43(0.30-0.63)$ & $<0.001$ & $0.48(0.32-0.72)$ & $<0.001$ \\
\hline
\end{tabular}

$\mathrm{AOR}=$ adjusted odds ratio; $\mathrm{CI}=$ confidence interval; Cutoff $<0.25$

${ }^{1}$ Adjusted for sex, SES, parental understanding, hygiene, physical activity and tobacco and other products.

${ }^{2}$ Adjusted for sex, SES, parental understanding, parental check, hygiene, physical activity and tobacco and other products

the recommended diet. Thus, the current scenario calls for in-depth understanding to improve the initiatives for nutritional guidelines and their application to adolescent population. This finding in Pakistan should serve as a warning sign for researchers to find the possible barriers to a recommended intake of fruit and vegetables among school adolescents.

Evidence suggests discrimination based on social markers. Children from marginalized groups are often more vulnerable to violence, both physical and psychological, than other children. South Asia is a deeply hierarchical society where children face discrimination based on ethnicity, religion and socio-economic status. In line with previous work, we found that children belonging to lower SES settings were more often bullied and experienced violence (32).

Children and adolescents may experience violence and bullying both at home and at school and in the real and virtual worlds. Those involved in bullying can be both victims and perpetrators. It is of essential importance for further research to focus on the interplay between healthy lifestyle, risk behaviours and the evolution of phenomena such as bully victimization and violence among adolescents.

GSHS used a validated and standardized questionnaire; cross-country comparisons are also possible in future. This is the first large nationally representative populationbased study conducted in Pakistan that has examined significant negative associations of healthy lifestyle behaviours with bullying and violence victimization. Our findings will hopefully advance the current understanding of healthy lifestyle behaviours and bullying problems among adolescents in low- and middle-income countries, especially in the South Asian region. Our observation that $94 \%$ adolescents do not consume the recommended daily allowance of fruit and vegetables may be of interest to nutritional researchers developing interventions for promoting healthy eating behaviours among adolescents. 


\section{Limitations}

The school enrolment rate in Pakistan is only 35\% (33) and since the data were collected from adolescents enrolled in schools, therefore the findings of our study may not be applicable to adolescents not attending school. All the data were self-reported by the students, which may subject to reporting bias. Moreover, the true prevalence of smoking among adolescents is likely to be overestimated since the current measure of cigarette smoking used does not distinguish between regular or experimental smokers. Due to the cross-sectional nature of the study, it is not possible to determine whether these factors are the determinants of being bullied or the consequences of it. Moreover, there are no questions in the survey that assessed both dependent and independent variables of the study in the same time frame. Therefore, we considered behaviour over the past 30 days as a proxy for behaviours over the previous year, assuming that behaviours adapted by children in the past reflect a more habitual behaviour developed over a period of time.

\section{Conclusion}

This study indicates that adapting healthy lifestyle behaviour may decrease bully victimization and violence among adolescents. The lower odds of victimization with physical activity and good hygienic practices demonstrate the health benefiting ability of such behaviours as compared to health compromising behaviours like smoking tobacco. Our study provides a general understanding of how different lifestyle domains are associated with bully victimization and violence among school-going adolescents. However, a more holistic approach, including social and emotional aspects of bullying behaviour, is required in order to address this multifaceted issue.

\section{Funding: None.}

Competing interests: None declared.

\section{Promotion d'un mode de vie sain comme mesure de prévention de la victimisation chez les adolescents scolarisés \\ Résumé}

Contexte : Le harcèlement et la violence sont des problèmes d'agression auxquels les adolescents sont confrontés. Les pratiques visant à promouvoir un mode de vie sain constituent des approches de promotion de la santé communément employées en milieu scolaire ; cependant le lien avec les comportements agressifs chez les adolescents scolarisés fait l'objet d'un moins grand nombre d'études.

Objectifs : La présente étude a examiné les liens entre les comportements associés à un mode de vie sain, y compris les bonnes règles d'hygiène, la pratique d'une activité physique, un régime alimentaire approprié et l'abstinence tabagique et la victimisation par harcèlement et la violence chez les adolescents.

Méthodes : Les données sont issues de l'enquête mondiale sur la santé dans les écoles réalisée au Pakistan (2009). La population d'étude était constituée d'adolescents scolarisés, âgés de 13 à 15 ans. Nous avons défini notre série définitive de données à l'aide des informations fournies par 4102 participants. Le lien entre les comportements associés à un mode de vie sain et la victimisation par harcèlement et la violence a été évalué au moyen d'une analyse de régression logistique multivariée.

Résultats : Les résultats font état de risques moins élevés de harcèlement (bonnes pratiques d'hygiène: OR = 0,62, IC à $95 \%$ 0,50-0,76, $p<0,001$; pratique d'une activité physique : OR = 0,55, IC à 95\% 0,40-0,75, $p<0,001$; abstinence tabagique : OR $=0,43$, IC à $95 \%$ 0,30-0,63, $p<0,001$ ) et risques moins élevés de violence (bonnes pratiques d'hygiène : OR = 0,68, IC à 95, $0,55-0,84 \%, p<0,001$; pratique d'une activité physique : OR = 0,55, IC à 95\% 0,43-0,71, $p<0,001$; abstinence tabagique : OR $=0,48$, IC à $95 \%$ 0,32-0,72, $p<0,001$ ), après élimination des facteurs socio-démographiques et des facteurs de confusion potentiels.

Conclusions : La présente étude vient confirmer l'importance d'un mode de vie sain en tant que mesure de prévention de la victimisation. Nous recommandons également que les programmes de lutte contre le harcèlement mettant l'accent sur le développement de compétences socio-émotionnelles intègrent la promotion auprès des adolescents de comportements associés à un mode de vie sain, dans le but de réduire la victimisation et ses conséquences connexes.

$$
\begin{aligned}
& \text { نمط الحياة الصحي بوصفه إجر اءً للوقاية من الإيذاء بين المراهقين الملتحقين بالمدارس } \\
& \text { نادية شاه، سعدية راو، سو مير إنعام، نيدا جو اد، تشارلوت سييجر، سيد عادل، كاشف شفيق } \\
& \text { الخالاصة }
\end{aligned}
$$

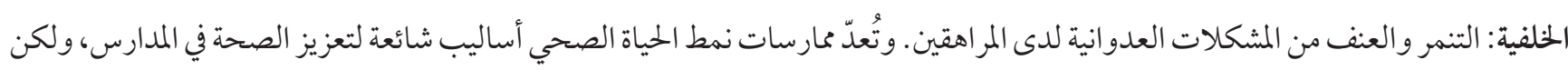

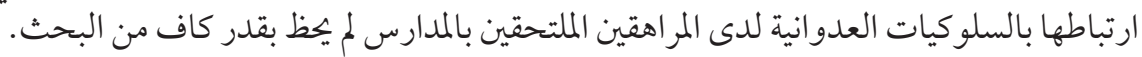

$$
\begin{aligned}
& \text { الأهداف: بحثت هذه الدراسة أوجه ارتباط سلو كيات نمط الحياة الصحي -ومنها النظافة الشخصية الجيدة والنشاط البدني واتباع النظام الغذائي }
\end{aligned}
$$




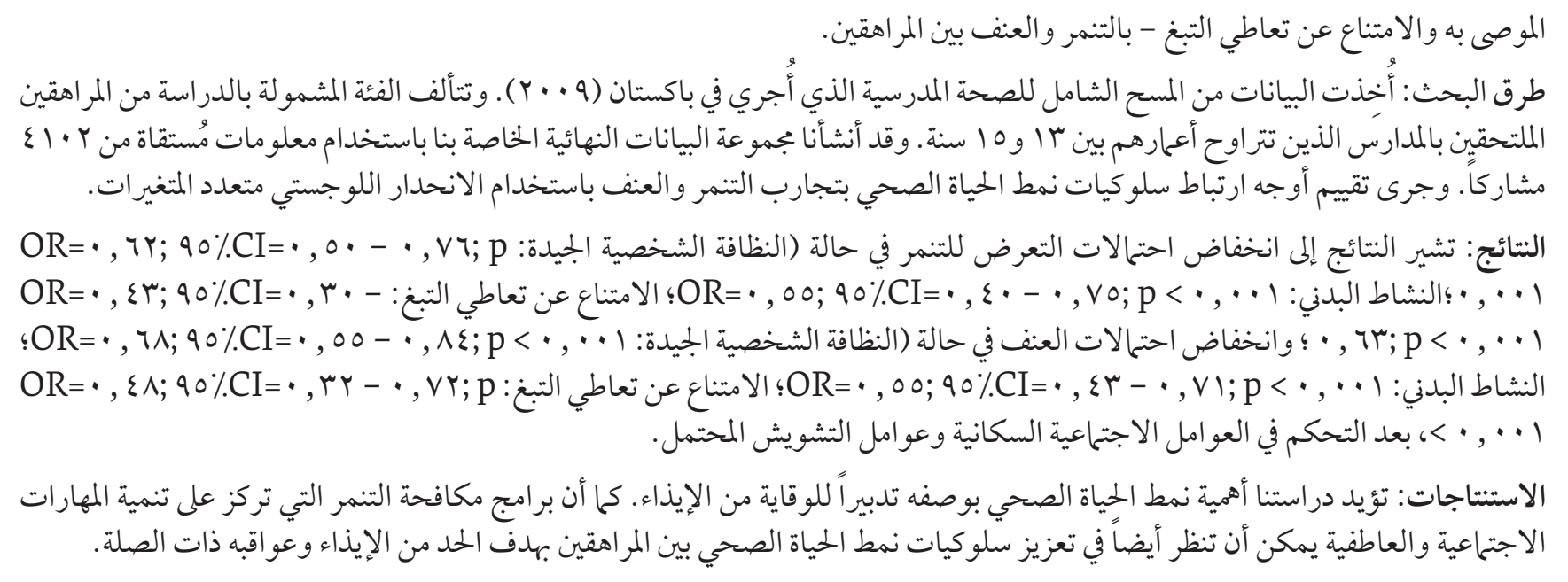

\section{References}

1. Olweus D. Aggression in the schools: Bullies and whipping boys. Hemisphere. 1978.

2. Juvonen J, Graham S, Schuster MA. Bullying among young adolescents: The strong, the weak, and the troubled. Pediatrics. 2003;112(6):1231-7.

3. World Health Organization. Violence prevention: An important element of a health-promoting school. Geneva: World Health Organization; 1998.

4. Hopkins L, Taylor L, Bowen E, Wood C. A qualitative study investigating adolescents' understanding of aggression, bullying and violence. Children and youth services review. 2013;35(4):685-93.

5. Fleming LC, Jacobsen KH. Bullying among middle-school students in low and middle income countries. Health Promot Int. 2010 Mar;25(1):73-84

6. Karmaliani R, Mcfarlane J, Somani R, Khuwaja HMA, Bhamani SS, Ali TS, et al. Peer violence perpetration and victimization: Prevalence, associated factors and pathways among 1752 sixth grade boys and girls in schools in Pakistan. PloS One. 2017; 12(8):e0180833.

7. Hills AP, King NA, Armstrong TP. The contribution of physical activity and sedentary behaviours to the growth and development of children and adolescents. Sports Med. 2007;37(6):533-45

8. Beyers JM, Toumbourou JW, Catalano RF, Arthur MW, Hawkins JD. A cross-national comparison of risk and protective factors for adolescent substance use: the United States and Australia. J Adolesc Health. 2004 Jul;35(1):3-16.

9. Åstrøm AN. Stability of oral health-related behaviour in a Norwegian cohort between the ages of 15 and 23 years. Community Dent Oral Epidemiol. 2004;32(5):354-62.

10. Kelishadi R, Ardalan G, Gheiratmand R, Gouya MM, Razaghi EM, Delavari A, et al. Association of physical activity and dietary behaviours in relation to the body mass index in a national sample of Iranian children and adolescents: CASPIAN Study. Bull World Health Organ. 2007 Jan;85(1):19-26.

11. Mamun A, O'Callaghan MJ, Williams G, Najman J. Adolescents bullying and young adults body mass index and obesity: a longitudinal study. Int J Obes. 2013;37(8):1140-6.

12. Pickett W, Dostaler S, Craig W, Janssen I, Simpson K, Shelley SD, et al. Associations between risk behavior and injury and the protective roles of social environments: an analysis of 7235 Canadian school children. Inj Prev. 2006 Apr; 12(2): 87-92.

13. Smith-Khuri E, Iachan R, Scheidt PC, Overpeck MD, Gabhainn SN, Pickett W, et al. A cross-national study of violence-related behaviors in adolescents. Arch Pediatr Adolesc Med. 2004 Jun;158(6):539-44.

14. Bollmer JM, Milich R, Harris MJ, Maras MA. A friend in need: The role of friendship quality as a protective factor in peer victimization and bullying. J Interpers Violence. 2005 Jun;20(6):701-12.

15. Khawaja S, Khoja A, Motwani K. Abuse among school going adolescents in three major cities of Pakistan: is it associated with school performances and mood disorders? JPMA The Journal of the Pakistan Medical Association. 2015;65(2):142.

16. Hyder AA, Malik FA. Violence against children: a challenge for public health in Pakistan. J Health Popul Nutr. 2007 Jun; 25(2):168-178.

17. Shujja S, Atta M, Shujjat JM. Prevalence of Bullying and Victimization among Sixth Graders with Reference to Gender, Socio-economic Status and Type of Schools. Sosyal Bilimler Dergisi/Journal of Social Sciences. 2014;38(2).

18. Pickett W, Molcho M, Simpson K, Janssen I, Kuntsche E, Mazur J, et al. Cross national study of injury and social determinants in adolescents. Inj Prev. 2005 Aug;11(4):213-8.

19. Kusumawardani N, Suhardi S. Behaviour health risk among adolescents: a school-based health survey with the focus on smoking in male adolescents aged 12-15 In depok, West Java, Indonesia. Buletin Penelitian Sistem Kesehatan. 2011;14(4 Okt). 
20. Turagabeci AR, Nakamura K, Takano T. Healthy lifestyle behaviour decreasing risks of being bullied, violence and injury. PloS One. 2008;3(2):e1585.

21. Agudo A. Measuring intake of fruit and vegetables. Geneva: World Health Organization; 2005.

22. Peltzer K, Pengpid S. Oral and hand hygiene behaviour and risk factors among in-school adolescents in four Southeast Asian countries. Int J Environ Res Public Health. 2014;11(3):2780-92.

23. Rudatskira E, Babaniyi O, Siziya S, Mulenga D, Muula AS, Mazaba-Liwewe ML. Correlates of bullying victimization among school-going adolescents in Algeria: Results from the 2011 global school-based health survey. Int J Med. Public Health. 2014;4(4).

24. Morris EB, Zhang B, Bondy SJ. Bullying and smoking: examining the relationships in Ontario adolescents. J Sch Health. 2006 Nov;76(9):465-70.

25. Janssen I, Craig WM, Boyce WF, Pickett W. Associations between overweight and obesity with bullying behaviors in schoolaged children. Pediatrics. 2004;113(5):1187-94.

26. Rao S, Shah N, Jawed N, Inam S, Shafique K. Nutritional and lifestyle risk behaviors and their association with mental health and violence among Pakistani adolescents: results from the National Survey of 4583 individuals. BMC Public Health. 2015;15(1):431.

27. Khawar R, Malik F. Bullying Behavior of Pakistani Pre-adolescents. Findings Based on Olweus Questionnaire. Pakistan Journal of Psychological Research. 2016;31(1):23.

28. Akram B, Munawar A. Bullying victimization: a risk factor of health problems among adolescents with hearing impairment. JPMA 2016;66(1):13-7.

29. Ruprah IJ, Sierra R: Mothers Are Right. Eat Your Vegetables And Keep Away From The Girls (Boys): Bullying Victimization Profile in the Caribbean. IDB Policy Brief 225; 2014.

30. Tian B, Zhang W, Qian L, Lv S, Tian X, Xiong G, et al. Health Behaviors and Protective Factors of School Students Aged 13-15 Years Old in Four Cities of China. Int Electron J Health Educ. 2007;10:35-59.

31. Kirkpatrick SI, Tarasuk V. Food insecurity is associated with nutrient inadequacies among Canadian adults and adolescents. J Nutr. 2008 Jul;138(7):1399.

32. Magklara K, Skapinakis P, Gkatsa T, Bellos S, Araya R, Stylianidis S, et al. Bullying behaviour in schools, socioeconomic position and psychiatric morbidity: a cross-sectional study in late adolescents in Greece. Child Adolesc Psychiatry Ment Health. $2012 ; 6: 8$.

33. Bank W. World Development Indicators: Participation in Education. Washington DC: World Bank; 2013. 